\title{
Assessing institutional capacities to adapt to climate change: integrating psychological dimensions in the Adaptive Capacity Wheel
}

\author{
T. Grothmann, K. Grecksch, M. Winges, and B. Siebenhüner \\ Ecological Economics, School of Computing Science, Business Administration, Economics and Law, University of \\ Oldenburg, Oldenburg, Germany
}

Correspondence to: T. Grothmann (torsten.grothmann@ uni-oldenburg.de)

Received: 2 January 2013 - Published in Nat. Hazards Earth Syst. Sci. Discuss.: 28 March 2013

Revised: 13 November 2013 - Accepted: 22 November 2013 - Published: 20 December 2013

\begin{abstract}
Several case studies show that social factors like institutions, perceptions and social capital strongly affect social capacities to adapt to climate change. Together with economic and technological development they are important for building social capacities.

However, there are almost no methodologies for the systematic assessment of social factors. After reviewing existing methodologies we identify the Adaptive Capacity Wheel (ACW) by Gupta et al. (2010), developed for assessing the adaptive capacity of institutions, as the most comprehensive and operationalised framework to assess social factors. The ACW differentiates 22 criteria to assess 6 dimensions: variety, learning capacity, room for autonomous change, leadership, availability of resources, fair governance.

To include important psychological factors we extended the ACW by two dimensions: "adaptation motivation" refers to actors' motivation to realise, support and/or promote adaptation to climate; "adaptation belief" refers to actors' perceptions of realisability and effectiveness of adaptation measures.

We applied the extended ACW to assess adaptive capacities of four sectors - water management, flood/coastal protection, civil protection and regional planning - in northwestern Germany. The assessments of adaptation motivation and belief provided a clear added value. The results also revealed some methodological problems in applying the ACW (e.g. overlap of dimensions), for which we propose methodological solutions.
\end{abstract}

\section{Introduction}

Assessments of adaptive capacity in climate change research developed from (climate) impact and vulnerability assessments (Füssel and Klein, 2006). "Climate impact assessments" only looked at exposure and sensitivity to climatic stimuli (e.g. changes in temperature or precipitation) to assess potential impacts of climate change. In the next phase of assessments, "first-generation vulnerability assessments", climate impacts were also evaluated in terms of their relevance for society. Furthermore, potential adaptation measures and non-climatic factors (such as environmental, economic, social, demographic, technological, and political factors) were considered. Later, "second-generation vulnerability assessments" explicitly included adaptive capacities of social and natural systems as well, thus shifting the focus from potential to feasible adaptation (for more detail see Füssel and Klein, 2006). Based on these conceptual developments, the 3rd Assessment Report of the Intergovernmental Panel on Climate Change (IPCC) defined vulnerability (to climate change) as "a function of the character, magnitude, and rate of climate variation to which a system is exposed, its sensitivity, and its adaptive capacity" (McCarthy et al., 2001, p. 995) ${ }^{1}$. This evolution of conceptual thinking in climate

\footnotetext{
${ }^{1}$ This definition of vulnerability is different from the understanding of vulnerability in natural hazards research. Nevertheless, despite the differences in definitions it appears that similar indicators and methodologies are used in the climate change and natural hazard community to assess potential future loss (Costa and Kropp, 2013).
} 
change vulnerability research highlights that social sciences were involved relatively late in the process.

The latest development in climate change vulnerability and adaptation research is the "shift from estimating expected damages to attempting to reduce them" (Füssel and Klein, 2006, p. 301). At the same time there was a shift from quantitative assessments of adaptive capacity (primarily at the national level) to assessments that help building adaptive capacity and reducing vulnerability (often at local and regional levels), applying transdisciplinary and qualitative research methods (Smit and Wandel, 2006). This development is very similar to the aim stated by Kuhlicke et al. (2011) for natural hazards research: to develop concepts for social capacity building.

In its 3rd assessment report the IPCC defined adaptive capacity as "the potential or ability of a system, region, or community to adapt to the effects or impacts of climate change" (Smit and Pilifosova, 2001, p. 881) and in the 4th assessment report - very similarly - as "the ability or potential of a system to respond successfully to climate variability and change" (Adger et al., 2007, p. 727). This minor change in the definition from the 3 rd to the 4 th assessment report is also a reflection of the relative high agreement among researchers in defining adaptive capacity concerning climate change.

Whereas first assessments of adaptive capacity focused on economic indicators (like GDP per capita, see IPCC, 1996), later studies increasingly recognised the importance of social factors like human and social capital for the adaptive capacity of social systems. The $3 \mathrm{rd}$ assessment report of the IPCC differentiated the following six general determinants of adaptive capacity: economic resources; technology; infrastructure; information and skills; institutions; equity (Smit and Pilifosova, 2001) $)^{2}$. Several case studies conducted since the 3rd assessment report show that social factors such as social capital, social networks, values, perceptions, interests, customs and traditions strongly determine the capability of social systems to adapt to risks related to climate change (Adger et al., 2007). Nevertheless, there is still "a clear shortfall in acknowledging social barriers to adaptation" (Jones and Boyd, 2011, p. 1262).

Social factors like perceptions of risks have a particular importance for reducing vulnerabilities and building social capacities because they can probably be changed easier and faster than social factors like economic, technological or infrastructural development, which often need longer time frames to be altered (see also Werg et al., 2013, in this issue). Jones and Boyd (2011) and Adger et al. (2009) argue similarly and stress the changeability of factors such as per-

\footnotetext{
${ }^{2}$ In the 4th assessment report the description of determinants of adaptive capacity is shorter than in the 3rd assessment report, but with a higher differentiation of different social factors: "The capacity to adapt is dynamic and influenced by economic and natural resources, social networks, entitlements, institutions and governance, human resources, and technology" (Adger et al., 2007, p. 719).
}

ceptions of risk, knowledge, experience, habitual behaviour, norms and values so that they act as (changeable) barriers to adaptation rather than as (fixed) limits. Therefore, assessments of such factors open up a promising perspective for increasing social capacities to adapt. For example, if adaptation to increasing flood risk in a particular locality can be realised by behavioural adaptations of its residents (e.g. by measures to stop floodwater from entering the buildings) an analysis of the social factors that hamper these behavioural adaptations (e.g. lack of risk perception in the community) can be used to identify which barriers have to be overcome to increase social capacities for adaptation.

Although the importance of social factors like institutions, perceptions and social capital for adaptive capacities of social systems has been shown in several case studies (for a recent overview see Jones and Boyd, 2011) there is a lack of standardised assessment concepts for these factors. Also in general, there is lack of systematic methodological development in social science research on climate change vulnerability and adaptation research (Grothmann et al., 2011).

The lack of systematic methodological development is partly due to the complexity and diversity of adaptation situations. Different sectors (water management, agriculture, health etc.), actors (government, business, civil society etc.), regions (mountainous, coastal, urban, rural etc.) and levels of decision-making (local, national, European, international etc.) are affected differently by climate change and its impacts (Grothmann, 2011). Therefore, also the necessary adaptations and adaptive capacities vary between these different social systems. Furthermore, even if the climate change problem addressed is the same, the determinants of adaptive capacities, the barriers to and drivers of adaptation processes seem to vary between different social systems.

In a study on adaptation to water scarcity in the European Alps, the conducted six regional case studies highlighted the diversity of the social factors hindering or driving the adaptation processes (Grothmann et al., 2009).

Nevertheless, for stimulating better learning between different social systems sensitive to climate change a more systematic methodological development for assessing social adaptive capacities and social barriers to adaptation seems promising. Even if the weighting of the indicators of adaptive capacities has to vary between different social systems (to correspond to existing differences) a systematic list of potentially influential social factors of adaptive capacities would be very helpful.

Gupta et al. (2010) have developed such a systematic list for assessing the adaptive capacity of institutions, the socalled Adaptive Capacity Wheel (ACW). In this paper we primarily describe how we extended the ACW to include important psychological determinants of institutional adaptive capacities not considered in the concept by Gupta et al. (2010).

Therefore, this paper focuses on the institutional dimension of adaptive capacities concerning climate change. We 
define institutions - like Gupta et al. (2010, p. 460) - according to the definition by the Institutions Project of the International Human Dimensions Programme as "systems of rules, decision-making procedures, and programs that give rise to social practices, assign roles to the participants in these practices, and guide interactions among the occupants of the relevant roles" (IDGEC, 1999, p. 14).

In the following, we first describe the ACW in more detail. Second, we show how we extended the ACW to include important psychological determinants of institutional adaptive capacities. Third, we explain how we applied the extended ACW to assess the adaptive capacities of water management, flood/coastal protection, civil protection and regional planning in northwestern Germany. In the final part of this article we discuss the methodological lessons we have learned from this test: the usefulness of the extended ACW to address important and as yet neglected dimensions of adaptive capacity but also methodological problems in the assessment, for which we propose several methodological solutions.

\section{Assessing institutional capacities: the Adaptive Capacity Wheel}

Some studies have empirically shown the importance of institutions for the capacity of social systems to adapt to climate change (e.g. Brooks et al., 2005; Grothmann et al., 2009; Tol and Yohe, 2007). There are also studies that have shown the importance of institutional factors for natural hazard management and disaster risk reduction (DRR) (e.g. Carey et al., 2012; Djalante et al., 2012).

Nevertheless, there is lack of concepts and methodologies to systematically assess capacities of institutions to adapt to climate change. Furthermore, while much of the climate change literature on adaptive capacity does mention institutions, the word is used quite loosely and often refers to organisations instead of systems of rules, decision-making procedures, and programs (Gupta et al., 2010, p. 460).

The Adaptive Capacity Wheel by Gupta et al. (2010) is the only highly operationalised methodology for assessing institutional capacities to adapt to climate change, with the claim to be applicable in a wide range of institutional settings. Other frameworks for assessing institutional adaptive capacities focus on sector-specific institutional settings. For example, Pahl-Wostl (2009) developed a framework for analysing resource governance systems (mainly water governance) to adapt to various stressors and changes, not only to climate change. Also Huntjens et al. (2012) developed institutional design propositions for the water sector, focusing on governance of adaptation to climate change. Hagedorn (2002) developed a conceptual framework for institutions relevant to efficient coordination between agricultural and environmental actors. Kuhlicke et al. (2011) outlined a typology of social capacities for natural hazards governance. Broader frameworks for institutional analysis, which often focus on socio- ecological systems (e.g. Folke et al., 2005; Ostrom, 2005, 2007, 2009), also claim, like Gupta et al. (2010), to be applicable in various institutional settings, but are not focusing, like Gupta et al. (2010), on climate change adaptation and were therefore not developed for addressing the specific challenges of climate change adaptation.

Based on Prutsch et al. (2014) we differentiate six main challenges for adaptation to climate change ${ }^{3}$ :

1. Uncertainty: most of the scientific projections of climate change and climate change impacts are highly uncertain, particularly at local and regional levels, where many of the adaptation decisions have to be taken.

2. Lack of knowledge: most of the scientific projections of climate change (impacts) are long term (e.g. 2050, 2100) and at global scale, whereas most adaptation decision-makers need short-term and local information.

3. Adaptation mainstreaming: for decision-makers, climate change is only one process among others and they have to integrate adaptation to climate change into existing structures and processes of decision-making. Furthermore, they need to integrate adaptation to climate change with adaptations to other developments like globalisation or demographic development.

4. Policy integration: adaptation is a highly complex issue due to the fact that climate change affects regions (e.g. mountainous, coastal), sectors (e.g. agriculture, water management), levels of decision-making (e.g. local, national) and actors (e.g. government, business) differently, but it is necessary to coordinate the adaptation measures of different regions, sectors, levels and actors to avoid conflicts and make use of synergies between different adaptation measures.

5. Equity: the achievement of social and ecological justice presents a further challenge for adaptation and also relates to disparities in climate change impacts and adaptation needs between different regions, sectors, actors, population groups and species. Governmental decision-makers often have the task to distribute the burden of impacts and adaptation measures fairly.

6. Adaptation barriers: the final challenge of adaptation poses the existence of multiple barriers (e.g. lack of

\footnotetext{
${ }^{3}$ The list of adaptation challenges proposed by Prutsch et al. can be used as a checklist for adaptive capacity frameworks. Such frameworks should include elements or dimensions that provide solutions for these challenges. One of the reasons why we have chosen the Adaptive Capacity Wheel by Gupta et al. as our framework for assessing adaptive capacity was that it explicitly or implicitly addresses all of the challenges listed by Prutsch et al. (see Table 1).
} 
financial resources or political will for adaptation, regulative barriers etc.) and the question how to tackle them.

All of these challenges are explicitly or implicitly addressed in the Adaptive Capacity Wheel by Gupta et al. (2010) (see Table 1). Furthermore, their framework is more operationalised and more specific regarding the criteria for assessing institutional adaptive capacities than other frameworks for assessing institutional adaptive capacities.

Gupta and her colleagues define institutional adaptive capacity as "the inherent characteristics of institutions that empower social actors to respond to short- and long-term impacts either through planned measures or through allowing and encouraging creative responses from society both ex ante and ex post. It encompasses:

- The characteristics of institutions (formal and informal; rules, norms and beliefs) that enable society (individuals, organizations and networks) to cope with climate change.

- The degree to which such institutions allow and encourage actors to change these institutions to cope with climate change" (Gupta et al., 2010, p. 461).

Integrating many of the previously described frameworks for institutional analyses and hereby combining insights on institutions, governance, management and on climate change adaptation and adaptive capacity, Gupta and her colleagues differentiate six dimensions of institutional adaptive capacity: variety, learning capacity, room for autonomous change, leadership, availability of resources and fair governance. In their view, institutions that promote adaptive capacity by necessity (1) "encourage the involvement of a variety of perspectives, actors and solutions" (variety); (2) "enable social actors to continuously learn and improve their institutions" (learning capacity); (3) "allow and motivate social actors to adjust their behaviour" (room for autonomous change); (4) "can mobilize leadership qualities" (leadership); (5) "can mobilize resources for implementing adaptation measures" (availability of resources); and (6) "support principles of fair governance" (fair governance) (Gupta et al., 2010, p. 461). These 6 dimensions and their 22 criteria form the Adaptive Capacity Wheel (ACW), which is shown (including our two new dimensions) in Fig. 1. Table 1 describes the 6 dimensions of the original ACW and their 22 criteria in more detail.

Gupta et al. (2010, p. 465) stress that there "can be tensions between the criteria; for example, between diversity of solutions and act according to plan", or between strong diversity of solutions and entrepreneurial leadership. Also, the fulfilment of some criteria may make others less relevant. "For example, if there is sufficient entrepreneurial leadership, this may displace the need for visionary leadership" (Gupta et al., 2010, p. 465). Furthermore, the dimensions and criteria are context-dependent. If applied to a specific sector, some

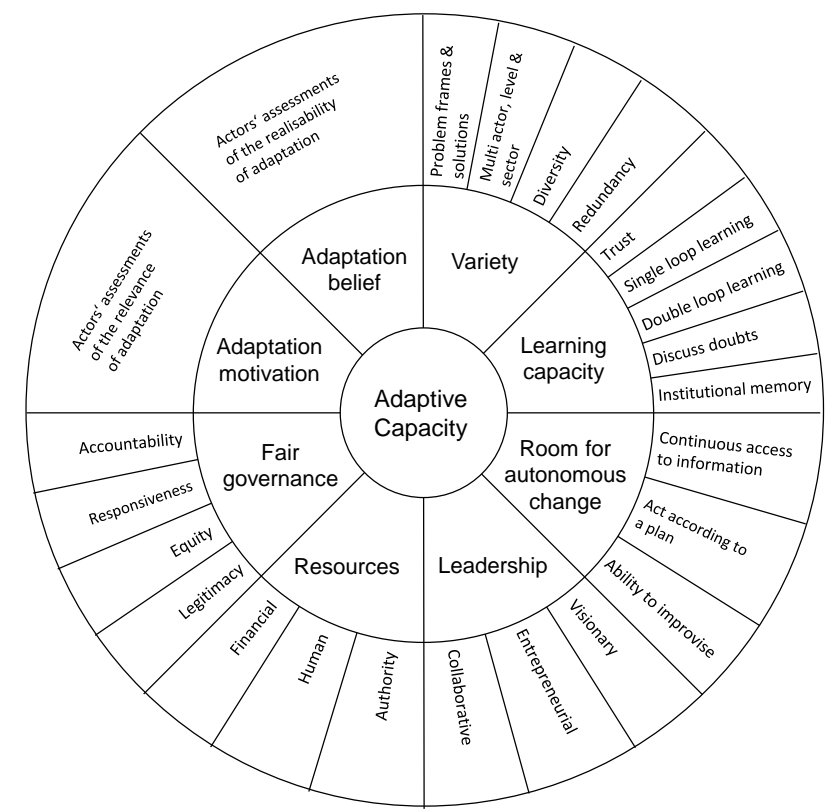

Fig. 1. Extended Adaptive Capacity Wheel - including two psychological dimensions.

dimensions and criteria may be more important than others so that they "are not additive in the sense that values given to each criterion can be simply added" (Gupta et al., 2010, p. 465).

Although the ACW has been developed to assess institutional adaptive capacities, its comparison with the categorisation of six general determinants of adaptive capacity in the 3rd assessment report of the IPCC (Smit and Pilifosova, 2001) (see Table 1) makes clear that it assesses not only institutional factors, but most other social factors of adaptive capacity included in the IPCC categorisation: information and skills, institutions, equity and also economic resources. Technology and infrastructure are not assessed, but the ACW is much more differentiated than the categorisation by the IPCC.

The comparison with the "Typology of social capacities" for dealing with natural hazards (Kuhlicke et al., 2011) (see Table 1) shows that there is a strong overlap with the ACW. Kuhlicke et al. have developed their typology also based on Gupta et al. (2010). Nevertheless, except for "Human resources" respectively "Knowledge capacities" the ACW is more differentiated than the "Typology of social capacities".

The comparison of the framework by Gupta et al. (2010) with the typology of Kuhlicke et al. (2011) supports our argument of a lack of an important social factor in the ACW and also in the categorisation of Smit and Pilifosova (2001): motivational capacities (see Table 1). In the next section we describe how we extended the ACW to include such important psychological capacities. 
Table 1. Comparison of Adaptive Capacity Wheel by Gupta et al. (2010) with other frameworks of adaptive or social capacities.

\begin{tabular}{|c|c|c|c|c|c|c|}
\hline \multicolumn{3}{|c|}{$\begin{array}{l}\text { Gupta et al. (2010, p. 462): } \\
\text { Dimensions and criteria of the Adaptive Capacity Wheel (ACW) }\end{array}$} & \multicolumn{2}{|c|}{$\begin{array}{l}\text { Kuhlicke et al. (2011, p. 806): Typology of } \\
\text { social capacities }\end{array}$} & \multirow{2}{*}{$\begin{array}{l}\text { Smit and Pilifosova } \\
\text { (2001, 895-897): } \\
\text { Determinants of adaptive } \\
\text { capacity }^{\mathrm{a}}\end{array}$} & \multirow{2}{*}{$\begin{array}{l}\text { Prutsch et al. } \\
\text { (2014): Adaptation } \\
\text { challenges addressed } \\
\text { by Gupta et al. (2010) }\end{array}$} \\
\hline Dimension & Criterion & Definition & Types of social capacities ${ }^{b}$ & Specification/description & & \\
\hline \multirow[t]{3}{*}{ 1. Variety } & $\begin{array}{l}\text { Variety of } \\
\text { problem frames }\end{array}$ & $\begin{array}{l}\text { Room for multiple } \\
\text { frames of references, } \\
\text { opinions and } \\
\text { problem definitions }\end{array}$ & & & No equivalent & \\
\hline & $\begin{array}{l}\text { Multi-actor, } \\
\text { multi-level, } \\
\text { multi-sector } \\
\text { Diversity of } \\
\text { solutions }\end{array}$ & $\begin{array}{l}\text { Involvement of different } \\
\text { actors, levels and sectors } \\
\text { in the governance process } \\
\text { Availability of a wide } \\
\text { range of different policy } \\
\text { options to tackle a problem }\end{array}$ & $\begin{array}{l}\text { Institutional } \\
\text { capacities }\end{array}$ & $\begin{array}{l}\text { Consideration of a variety } \\
\text { of problem frames, } \\
\text { multi-actor, multi-level, } \\
\text { multi-sector, diversity of } \\
\text { solutions and redundancy }\end{array}$ & No equivalent & $\begin{array}{l}\text { Uncertainty, lack of } \\
\text { knowledge, adaptation } \\
\text { mainstreaming, } \\
\text { policy integration }\end{array}$ \\
\hline & $\begin{array}{l}\text { Redundancy } \\
\text { (duplication) }\end{array}$ & $\begin{array}{l}\text { Presence of overlapping } \\
\text { measures and back-up } \\
\text { systems; } \\
\text { not cost-effective }\end{array}$ & & & No equivalent & \\
\hline \multirow[t]{5}{*}{$\begin{array}{l}\text { 2.Learning } \\
\text { capacity }\end{array}$} & Trust & $\begin{array}{l}\text { Presence of institutional } \\
\text { patterns that promote } \\
\text { mutual respect and trust }\end{array}$ & $\begin{array}{l}\text { Network } \\
\text { capacities }\end{array}$ & $\begin{array}{l}\text { Possession or development of } \\
\text { the ability to establish and } \\
\text { stabilise trustful relationships } \\
\text { among and between different } \\
\text { organisational, local and } \\
\text { individual actors }\end{array}$ & No equivalent & \\
\hline & $\begin{array}{l}\text { Single loop } \\
\text { learning }\end{array}$ & $\begin{array}{l}\text { Ability of institutional patterns } \\
\text { to learn from past experiences } \\
\text { and improve their routines }\end{array}$ & No equivalent & & No equivalent & \\
\hline & $\begin{array}{l}\text { Double loop } \\
\text { learning }\end{array}$ & $\begin{array}{l}\text { Evidence of changes } \\
\text { in assumptions underlying } \\
\text { institutional patterns }\end{array}$ & No equivalent & & No equivalent & $\begin{array}{l}\text { Uncertainty, lack of } \\
\text { knowledge, adaptation } \\
\text { mainstreaming, }\end{array}$ \\
\hline & Discuss doubts & $\begin{array}{l}\text { Institutional openness } \\
\text { towards uncertainties }\end{array}$ & No equivalent & & No equivalent & $\begin{array}{l}\text { policy integration, } \\
\text { equity, } \\
\text { adaptation barriers }\end{array}$ \\
\hline & Institutional & $\begin{array}{l}\text { Institutional provision } \\
\text { of monitoring and } \\
\text { evaluation processes of } \\
\text { policy experiences }\end{array}$ & No equivalent & & No equivalent & \\
\hline \multirow[t]{3}{*}{$\begin{array}{l}\text { 3. Room for } \\
\text { autonomous } \\
\text { change }\end{array}$} & $\begin{array}{l}\text { Continuous access } \\
\text { to information }\end{array}$ & $\begin{array}{l}\text { Accessibility of data } \\
\text { within institutional } \\
\text { memory and early warning } \\
\text { systems to individuals }\end{array}$ & No equivalent & & Equity & \\
\hline & $\begin{array}{l}\text { Act according } \\
\text { to plan }\end{array}$ & $\begin{array}{l}\text { Increasing the ability of } \\
\text { individuals to act by providing } \\
\text { plans and scripts for action, } \\
\text { especially in case of disasters }\end{array}$ & No equivalent & & Institutions & $\begin{array}{l}\text { Uncertainty, } \\
\text { lack of knowledge, } \\
\text { equity }\end{array}$ \\
\hline & $\begin{array}{l}\text { Capacity to } \\
\text { improvise }\end{array}$ & $\begin{array}{l}\text { Increasing the capacity of } \\
\text { individuals to self-organise } \\
\text { and innovate; foster } \\
\text { social capital }\end{array}$ & No equivalent & & Institutions & \\
\hline \multirow[t]{3}{*}{ 4. Leadership } & Visionary & $\begin{array}{l}\text { Room for long-term visions } \\
\text { and reformist leaders }\end{array}$ & No equivalent & & No equivalent & \\
\hline & Entrepreneurial & $\begin{array}{l}\text { Room for leaders that } \\
\text { stimulate actions and } \\
\text { undertakings; leadership } \\
\text { by example }\end{array}$ & No equivalent & & No equivalent & $\begin{array}{l}\text { Adaptation mainstreaming, } \\
\text { policy integration, equity, } \\
\text { adaptation barriers }\end{array}$ \\
\hline & Collaborative & $\begin{array}{l}\text { Room for leaders who } \\
\text { encourage collaboration } \\
\text { between different } \\
\text { actors; adaptive } \\
\text { co-management }\end{array}$ & Network capacities & $\begin{array}{l}\text { Possession and exploitation } \\
\text { of social capital, that is, } \\
\text { the aggregate of the actual } \\
\text { or potential resources which } \\
\text { are linked to possession of } \\
\text { a durable network of more } \\
\text { or less institutionalised } \\
\text { relationships of mutual } \\
\text { acquaintance recognition }^{c}\end{array}$ & No equivalent & \\
\hline
\end{tabular}


Table 1. Continued.

\begin{tabular}{|c|c|c|c|c|c|c|}
\hline \multicolumn{3}{|c|}{$\begin{array}{l}\text { Gupta et al. (2010, p. 462): } \\
\text { Dimensions and criteria of the Adaptive Capacity Wheel (ACW) }\end{array}$} & \multicolumn{2}{|c|}{$\begin{array}{l}\text { Kuhlicke et al. (2011, p. 806): Typology of } \\
\text { social capacities }\end{array}$} & \multirow{2}{*}{$\begin{array}{l}\text { Smit and Pilifosova } \\
(2001,895-897) \text { : } \\
\text { Determinants of adaptive } \\
\text { capacity }^{\mathrm{a}}\end{array}$} & \multirow{2}{*}{$\begin{array}{l}\text { Prutsch et al. } \\
\text { (2014): Adaptation } \\
\text { challenges addressed } \\
\text { by Gupta et al. (2010) }\end{array}$} \\
\hline Dimension & Criterion & Definition & Types of social capacities ${ }^{b}$ & Specification/description & & \\
\hline \multirow[t]{3}{*}{ 5. Resources } & Authority & $\begin{array}{l}\text { Provision of accepted or legitimate } \\
\text { forms of power; whether or not } \\
\text { institutional rules are embedded } \\
\text { in constitutional laws }\end{array}$ & No equivalent & & No equivalent & \\
\hline & $\begin{array}{l}\text { Human } \\
\text { resources }\end{array}$ & $\begin{array}{l}\text { Availability of expertise, } \\
\text { knowledge and human labour }\end{array}$ & Knowledge capacities & $\begin{array}{l}\text { Knowledge about the hazard and } \\
\text { the risk; knowledge about how } \\
\text { to prepare for, cope with } \\
\text { and recover from the negative } \\
\text { impact of a hazard; knowledge } \\
\text { about other actors involved in } \\
\text { the handling of hazards and disasters; } \\
\text { knowledge about formal institutions } \\
\text { such as legal frameworks and } \\
\text { specific laws; knowledge } \\
\text { about underlying informal values, } \\
\text { norms and beliefs of different actors }\end{array}$ & Information and skills & $\begin{array}{l}\text { Uncertainty, } \\
\text { lack of knowledge, } \\
\text { adaptation barriers }\end{array}$ \\
\hline & $\begin{array}{l}\text { Financial } \\
\text { resources }\end{array}$ & $\begin{array}{l}\text { Availability of financial resources } \\
\text { to support policy measures and } \\
\text { financial incentives policy measures }\end{array}$ & Economic capacities & Availability of financial resources & Economic resources & \\
\hline \multirow[t]{4}{*}{$\begin{array}{l}\text { 6. Fair } \\
\text { governance }\end{array}$} & Legitimacy & $\begin{array}{l}\text { Whether there is public support } \\
\text { for a specific institution }\end{array}$ & & & No equivalent & \\
\hline & & $\begin{array}{l}\text { Whether or not institutional } \\
\text { rules are fair }\end{array}$ & \multirow[t]{3}{*}{$\begin{array}{l}\text { Institutional } \\
\text { capacities }\end{array}$} & \multirow{3}{*}{$\begin{array}{l}\text { Consideration of principles of fair } \\
\text { governance (legitimacy, equity, } \\
\text { transparency, responsiveness } \\
\text { and accountability) }\end{array}$} & Equity & \multirow{3}{*}{$\begin{array}{l}\text { Adaptation mainstreaming, } \\
\text { policy integration, } \\
\text { equity, } \\
\text { adaptation barriers }\end{array}$} \\
\hline & Responsiveness & $\begin{array}{l}\text { Whether or not institutional patterns } \\
\text { show response to society }\end{array}$ & & & No equivalent & \\
\hline & Accountability & $\begin{array}{l}\text { Whether or not institutional } \\
\text { patterns provide accountability } \\
\text { procedures }\end{array}$ & & & & \\
\hline \multicolumn{3}{|l|}{ No equivalent } & Motivational & $\begin{array}{l}\text { Motivation to prepare for, cope with } \\
\text { and recover from the negative impact of } \\
\text { a hazard. Building a sense of responsibility } \\
\text { for one's own actions but also for those of } \\
\text { other actors }\end{array}$ & No equivalent & \\
\hline \multicolumn{3}{|l|}{ No equivalent } & \multicolumn{2}{|l|}{ No equivalent } & \multicolumn{2}{|l|}{ Technology } \\
\hline \multicolumn{3}{|l|}{ No equivalent } & \multicolumn{2}{|l|}{ No equivalent } & \multicolumn{2}{|l|}{ Infrastructure } \\
\hline
\end{tabular}

\section{Integrating psychological dimensions in assessments of institutional adaptive capacities}

Although Gupta et al. (2010, p. 461) define "beliefs" (a psychological term) as an element of institutions, they neglect their role in the ACW. This neglect is consistent with larger climate change research, which generally overlooks the role of psychological factors (Grothmann and Patt, 2005; O'Brien, 2009).

In the following, we argue for the importance of psychological factors in assessments of institutional adaptive capacities. In order to address important psychological determinants of adaptive capacity - as yet not considered in the approach by Gupta et al. - we included "adaptation motivation" and "adaptation belief" (based on Grothmann and

\footnotetext{
${ }^{4}$ We use these terms instead of the psychologically more precise terms "risk/chances perception" and "controllability beliefs" to achieve wider and easier understandability.
}

Patt, 2005; Grothmann et al., 2009) in an extended version of the ACW, which now has eight dimensions (see Fig. 1).

Before we describe these two additional determinants of adaptive capacity in more detail we want to specify what we mean by psychological determinants. Psychological or subjective factors like individual adaptation motivation or adaptation belief of a decision-maker in an organisation are a result of "subjective" perceptions of "objective" climate change projections, organisational contexts (e.g. financial resources, institutional entitlements, negotiations between different actors in an organisation) and the wider institutional environment influencing and shaping both the organisational roles and responsibilities as well as individuals' motivations and beliefs. Hence, these psychological or subjective factors are not independent of the objective contexts. "Subjective" assessments of adaptation motivations or adaptation beliefs individuals provide in interviews (see Sect. 4) are not exclusively their personal ones, but also that of organisations and 
the broader institutional setting interview partners are representing. Nevertheless, these "subjective" assessments can be very different from what the "objective" contexts might look like to an outside observer. Therefore it is necessary to interview actors as representatives of institutional settings to understand their motivations and beliefs as important elements of institutional adaptive capacities. Adaptation motivation refers to actors' motivations to realise, support and/or promote adaptation to climate change. If there is a lack of adaptation motivation of decision-makers in a social system its adaptive capacity is reduced because there is lack of political will for adaptation (Grothmann et al., 2009; Grothmann, 2011). The main determinant of the adaptation motivation is the perception of risks (or: risk appraisal) and/or chances of climate change and its potential impacts ${ }^{5}$. The risk/chances perception expresses the perceived probability of being exposed to climate change impacts and to the appraisal of how harmful/useful these impacts would be to things that an actor values. Perceptions of climate change risks and/or chances have been shown as important determinants of adaptation in various empirical studies, at household level (e.g. Grothmann and Patt, 2005; Weber, 1997), organisational level (e.g. Berkhout, 2012) and at community level (e.g. Jones and Boyd, 2011). Therefore, Adger (2006, p. 268) concludes that "the challenges for vulnerability research are [...] to incorporate diverse methods that include perceptions of risk and vulnerability". More comprehensively, Adger et al. (2009, p. 339) argue "that social and individual factors limit adaptation action. Factors such as perception of risk, habit, social status and age operate at individual decisionmaking levels but also constrain collective action. Individual adaptation hinges on whether an impact, anticipated or experienced, is perceived as a risk and whether it should (and could) be acted upon. At the policy level, adaptation policies, like many other areas of public policy, are constrained by inertia, cultures of risk denial, and other phenomena well known in policy sciences. We suggest that individual and social characteristics, in particular risk perception, interact with underlying values to form subjective and mutable limits to adaptation that currently hinder society's ability to act."

Kuhlicke et al. (2011, p. 806) refer to this psychological factor by "Motivation to prepare for, cope with and recover from the negative impact of a hazard". Many climate change adaptation guidelines (e.g. UNDP, 2010) and some scientific authors (e.g. Moser and Ekstrom, 2010) speak of "awareness" of climate change and its impacts instead of risk perception, but basically mean the same.

But if adaptation motivation really leads to adaptation measures is decided upon a cognitive factor that is disregarded in the adaptation literature (also by Kuhlicke et al.,

\footnotetext{
${ }^{5}$ In our empirical studies (see Sect. 4) we assessed adaptation motivation via interviewees' perceptions of relevance of adaptation to climate change. The reasons for this assessment procedure are explained in detail in Sect. 4.1.1.
}

2011): adaptation belief (similar concepts are: adaptation appraisal, perceptions of self-efficacy and outcome-efficacy, control beliefs, perceived adaptive capacity; see Grothmann and Patt, 2005). Adaptation belief refers to an "I/we can successfully adapt to climate change"-conviction. Figure 2 illustrates that adaptation beliefs can be assessed either by asking actors whether they believe that they can successfully adapt to climate change (control belief) or by asking actors whether they believe that there are adaptation measures available, which are effective (outcome-efficacy belief) and realisable by them (self-efficacy belief).

The "objective" ability or capacity of a human actor (e.g. available financial resources, institutional entitlements) only partly determines if an adaptive response is taken. Even as important as the "objective" ability is the subjective or perceived ability of human actors (i.e. adaptation belief) because the subjective ability can be very different from the "objective" ability. People and decision-makers can under- and overestimate their action scope. "Because climate change is a global problem, many individuals understandably believe that they can do nothing about it" (APA, 2010, p. 67). Adger et al. (2009, p. 344) also argue for the importance of "perceptions of self-efficacy and controllability" and that these, together with perceptions of risk and other psychological factors, determine what is perceived to be a limit to adaptation at both individual and social levels. There are also studies that explicitly show that low adaptation beliefs can become barriers to adaptation of private households (e.g. Grothmann and Patt, 2005) and communities (e.g. Jones and Boyd, 2011). Hence, there could be a systematic bias towards underestimating the capacity to adapt to climate change impacts. We are not proposing that objective aspects of adaptive capacity (see above) are insignificant determinants of adaptive capacity and adaptation. They are included in the ACW by Gupta et al. (2010) in the resources dimension. "But if agents systematically underestimate their own ability to adapt, this qualifies as a more important 'bottleneck' for adaptation than the objective physical, institutional or economic constraints" (Grothmann and Patt, 2005, p. 203).

In other words, it seems highly improbable that any actor or decision-maker would take measures to adapt to climate change without the perception that adaptation is necessary/useful (adaptation motivation) and possible (adaptation belief). Whereas the adaptation motivation refers to an "I/we want to adapt"-conviction, the adaptation belief refers to an "I/we can adapt"-conviction. Kuhlicke et al. (2011, p. 806) refer to another potentially important psychological factor: "sense of responsibility for one's own actions but also for those of other actors". We refrained from including such a normative/moral "I/we should adapt"-conviction in our extended ACW because as yet we do not know of any empirical proof of its influence on adaptive capacity or adaptation to climate change. Nevertheless, such an inclusion might become necessary in the future, if climate change adaptation 


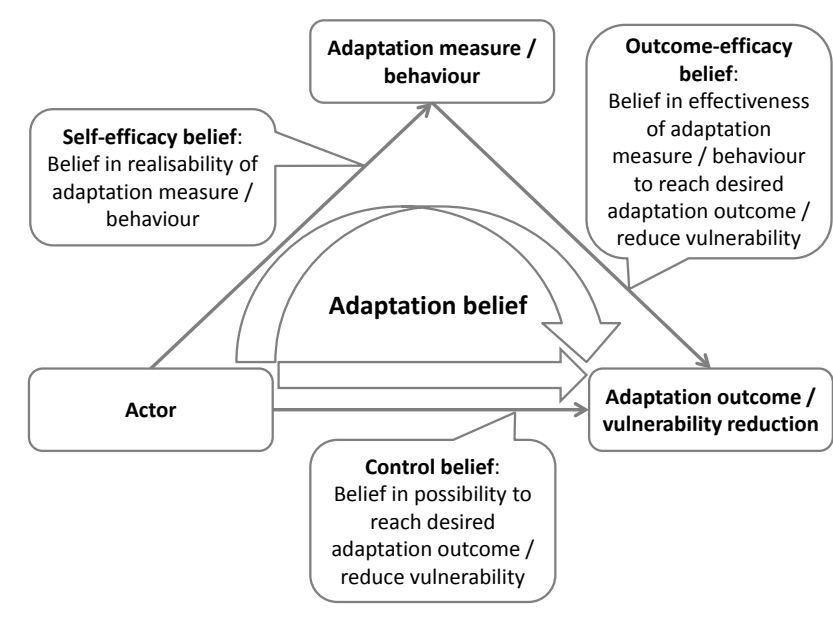

Fig. 2. Illustration of the adaptation belief concept and ways to assess it (developed from Hoff and Walter, 1996).

becomes a social norm and influences people's adaptation decisions.

Adaptation motivation and adaptation belief are central factors of various psychological models explaining human behaviour in the context of natural hazards. Protection Motivation Theory (PMT; Rogers, 1983; Rogers and PrenticeDunn, 1997) differentiates threat appraisal and coping appraisal. Threat appraisal is basically the same as risk perception, which is - besides the perception of chances of climate change - the main determinant of adaptation motivation. Coping appraisal is very similar to adaptation belief. The Person-relative-to-event (PrE) model (Mulilis and Duval, 1997) conceptualises the relation between perceived risks and the perceived opportunities to prevent harm from these risks as the main determinant of preventive behaviour. The Protective Action Decision Model (PADM) (Lindell and Perry, 1992; Lindell and Perry, 2012) identifies three core perceptions - threat perceptions (similar to risk perceptions), protective action perceptions (similar to adaptation belief), and stakeholder perceptions - that form the basis for decisions about how to respond to an imminent or long-term threat. All models have successfully been applied in many studies in the natural hazards context and it has been shown in most studies that risk perceptions and perceptions of the possibility and the effectiveness of protective behaviour strongly influence such behaviour.

By including adaptation motivation and adaptation belief in the ACW we selected two of the many psychological factors that can influence the adaptive capacity of a social system. We see these two factors as empirically well proven, as particularly important and necessary factors for adaptation, but do not understand them as sufficient to overcome the large number of potential psychological barriers to adaptation.
Further psychological factors - apart from a lack of adaptation motivation or adaptation belief - can decrease the chances for adaptation. Sometimes they influence adaptation motivation and adaptation belief, sometimes they do not. These psychological factors can be goals, aspirations or worries that are perceived as more important than or inconsistent with adaptation to climate change (e.g. "Let's first address climate change mitigation before we deal with adaptation"; finite pool of worry hypothesis), a lack of perceived fairness ("Why should I/my organization/my sector adapt to climate change when others don't?"; tragedy of the commons hypothesis) or a general tendency to procrastinate action. Furthermore, people may lack the necessary individual competencies for effectively getting involved in adaptation action (see Grothmann and Siebenhüner, 2012).

Therefore, the following statement by Gupta et al. (2010, p. 465) still holds: "even if an institution appears to create adaptive capacity, this does not automatically mean that society will use this capacity". Even with the inclusion of adaptation motivation and adaptation belief in the ACW, a high adaptive capacity based on an assessment by the extended $\mathrm{ACW}$ is no guarantee that adaptation will take place, but our hypothesis is that it would indicate a higher probability for adaptation than just based on the original, six-dimensional ACW by Gupta et al. (2010).

\section{Measuring adaptive capacities in northwestern Ger- many - a case study in four climate sensitive sectors}

We empirically tested the extended ACW within the project "nordwest2050" in the metropolitan area BremenOldenburg, which is a region of northwestern Germany with more than 2.3 million inhabitants. Part of the project was an analysis of institutional capacities to adapt to potential climate change impacts (sea level rise, storm surges, river flooding, droughts etc.) in the region, focusing on four climate sensitive sectors: water management, flood/coastal protection, civil protection and spatial/regional planning.

These sectors were chosen from the list of climate sensitive sectors named in the German Strategy for Adaptation to Climate Change (2008) due to their particular relevance for adaptation to climate change in Germany's northwestern region.

In operationalising the extended ACW we generally followed the research protocol described by Gupta et al. (2010, 465-466). They differentiate five steps:

1. Preparing for the research (mainly: identification of a clear research focus on a particular institution or institutional context; here: water management, flood/coastal protection, civil protection and spatial/regional planning in northwestern Germany);

2. Collecting the data by various methods (for each criterion of the ACW; see Sect. 4.1.1); 
3. Analysing the data (mainly: score each criterion of the ACW; see Sect. 4.1.2);

4. Interpreting the data (translate the information collected into a story that communicates the strengths and weaknesses of the analysed institution in terms of adaptive capacity; see Sect. 4.2);

5. Presenting the data (mainly: visualise the strengths and weaknesses by using grey tones or traffic light system to colour the ACW; see Fig. 3).

In the following, we focus on the methodological procedures we applied to assess adaptation motivation and adaptation belief.

\subsection{Methods}

\subsubsection{Data collection}

To get an understanding of the institutional adaptive capacities in the four sectors we conducted a literature review, document analyses, and half-standardised interviews.

The literature review included scientific studies that assessed impacts of and vulnerabilities to climate change in northwestern Germany. After identifying these studies (peerreviewed articles, reports without peer review etc.) they were systematically reviewed. Although several studies analysed potential climate change impacts in northwestern Germany, no study assessed the institutional capacities to adapt to these impacts in the region.

The document analyses reviewed mainly governmental documents because very few documents from NGOs or business organizations refer to climate change adaptation or adaptive capacities. Our analyses included formal and informal documents relevant for the study region, such as official governmental reports of the federal states Bremen and Lower Saxony, official documents from federal parliaments (e.g. protocols of parliamentary meetings), laws, regulations and press releases. The relevant documents were identified by an internet search and by reviewing documents and laws relevant for the analysed sectors. Important documents were also named by the interview partners (see next paragraph). We tried to identify as many documents as possible that included relevant information for assessing the eight dimensions of the ACW. Nevertheless, as Fig. 3 shows that for the example of water management in northwestern Germany, we could not assess some criteria due to lack of data.

The most important data for assessing the criteria of the extended ACW came from half-standardised interviews with actors and stakeholders who have knowledge about adaptation measures and potential climate change impacts in the four sectors addressed. The interview partners were identified based on an analysis of relevant organisations in the sectors. Within the identified organisations we asked for people who are knowledgeable about potential climate change im-
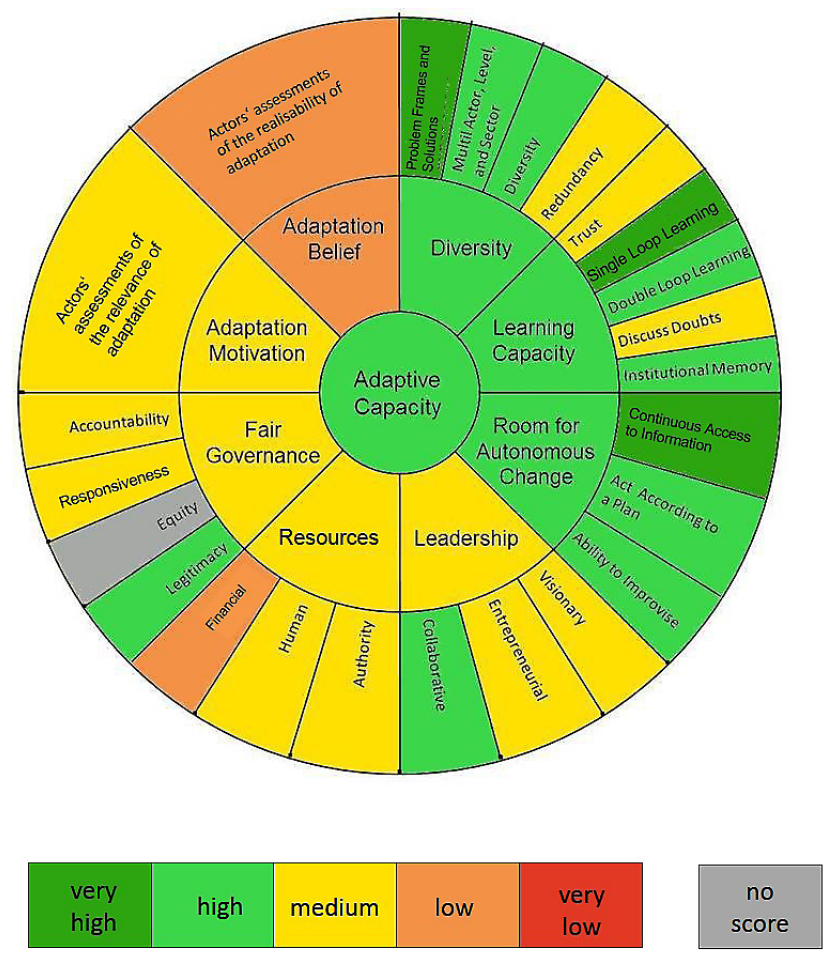

Fig. 3. Exemplary Adaptive Capacity Wheel for water management in northwestern Germany (cf. Grecksch, 2013b).

pacts and feasible adaptation measures in the respective sectors. Depending on the willingness of the contacted persons, we could conduct three to ten interviews per sector (civil protection: 3 ; water management: 5 ; flood/coastal protection: 5 ; spatial/regional planning: 10). Most of the interview partners were mainly administrative officers and employees in expert organisations (e.g. dike associations), who are responsible for given tasks (e.g. flood protection). These actors also inform politicians and decision-makers in the governmental organisations. ${ }^{6}$

The half-standardised interviews lasted one to two hours and were conducted based on methodologies for focused, problem-centred and expert interviews (cf. Fowler and Mangione, 1990; Merton and Kendall, 1946/1979; Meuser and Nagel, 1991; Witzel, 1985, 2000). These methods restrict the

\footnotetext{
${ }^{6}$ Although institutions are systems of rules and procedures and not identical with organisations (see definition of institutions in Sect. 1), for some sectors - including the four sectors analysed here - many of the existing rules and procedures are formalised within organisational settings or the organisations follow rules (e.g. laws) set by other organisations/social systems (e.g. parliaments). The institutions for water management, flood/coastal protection, civil protection and spatial/regional planning are highly formalised in Germany within governmental organisational settings. Hence, we primarily interviewed representatives from governmental organisations and primarily analysed documents from governmental organisations.
} 
information that is expected from interview partners more than other interview techniques, but are sufficiently open to allow respondents to name aspects that are not addressed in the interview guideline. The interviews were tape recorded and partly transcribed.

The interviews started with a question regarding the fields of activity of the organisation the interview partner is working for (including the region the organisation is responsible for) and regarding the fields of activity of the interview partner him- or herself. Then interview partners were asked to describe the risks and chances of climate change they perceive for their respective sector (civil protection, water management, flood/coastal protection or spatial/regional planning) in northwestern Germany within the next $40 \mathrm{yr}$. As an indicator of learning capacity we then asked whether their organisation is currently exchanging information and or cooperating in another way with other organisations with regard to risks and chances of climate change.

After that adaptation motivation was assessed by the following question: "Which relevance does adaptation to climate change currently have in your organisation? I am not asking for the relevance of mitigation of climate change (that is: reduction of greenhouse gas emissions) but only for the relevance of adaptation to climate change. Please rate the relevance of climate change adaptation in your organisation on the following scale [visual presentation of the scale]: no relevance, small relevance, medium relevance, high relevance. Please consider in your rating also other current challenges of your organisation, with which adaptation to climate change probably competes." It has been argued in Sect. 3 that the main determinant of adaptation motivation is the perception of risks (or: risk appraisal) and/or chances of climate change and its potential impacts. Nevertheless, we assessed adaptation motivation in this study via the perceived relevance of adaptation to climate change in the organisations of the interview partners. Most of the interview partners represented organisations in which adaptation to climate change has not yet or not deeply been discussed (especially not a top levels of organisations). We knew from previous studies (e.g. Zebisch et al., 2005) that a question asking for perceptions of risks in the organisations would have resulted in many "don't know" answers because organisational representatives do not want to make statements about risks, when there is a lack of formalised organisational risk assessments and organisational discourse on climate change risks has just started. Therefore, we decided to measure adaptation motivation by a question asking for the perceived relevance of adaptation in the organisations. This was a question which the interviewees were willing to answer. Certainly, perceived relevance of adaptation and adaptation motivation are not identical but if an issue is regarded as relevant in an organisation there is a high probability that there is also an 'organisational motivation' to deal with this issue.

After the interview partners had rated the relevance of adaptation in their organisations they were asked to answer which of the current measures to prevent harm (e.g. current dykes) would be insufficient to prevent harm in the future considering scenarios of climate change and climate change impacts for 2050 and 2085 (e.g. sea-level rise). A short description of these scenarios was sent to the interview partners before the interviews.

Adaptation belief was then assessed by interview partner ratings of the realisability of sector-specific adaptation measures they regarded as necessary and effective. Therefore, in this study adaptation belief was measured by assessing selfefficacy beliefs and outcome-efficacy beliefs (see Sect. 3). More specifically, we generated indicators of adaptation beliefs in the following way. First, the interview partners read a list of potential sector-specific adaptation measures that was generated from the German Strategy for Adaptation to Climate Change (2008), which names feasible adaptation measures for various climate sensitive sectors. Second, the interviewers openly discussed these measures with the interview partners to gain an understanding, which of them they see as most needed and effective for avoiding the risks and make use of the chances of climate change for their sector in the region. Third, the interview partners were asked to select three adaptation measures that are - according to their opinion - most needed and effective (indicating outcome-efficacy beliefs). Fourth, for each of these three measures they were asked, (a) which barriers to realising the adaptation measures and (b) which potential synergies with other useful measures (e.g. with mitigation measures) they perceive. Fifth and finally, - as the main indicator of adaptation belief - interview partners answered the following question for each of the three measures: "On the background of the barriers and potential synergies you have named: how realisable do you assess the measure? Please rate the realisability on the following scale: not at all realisable, difficult to realise, realisable, easy to realise" (indicating self-efficacy beliefs ${ }^{7}$ ).

The interview ended with two questions that aimed at measuring room for autonomous change: How well could your sector (civil protection, water management, flood/coastal protection or spatial/regional planning) implement new strategies, plans, laws and regulations in northwestern Germany in the past? How well has your sector adapted flexibly to unexpected problems or crises in northwestern Germany in the past?

Hence, in addition to the questions on adaptation motivation and adaptation belief, the interviews explicitly included questions regarding learning capacity and room for autonomous change. Due to the restricted time of the

\footnotetext{
${ }^{7}$ To be precise, this question addresses less a self-efficacy ("I can realise this adaptation measure") than a collective-efficacy belief ("We/my organisation/my sector can realise this adaptation measure"). Since most adaptation measures have to be realised collectively, often cooperatively by different organisations or governmental bodies, this actor-unspecific formulation of the question appeared adequate.
} 
interviews, not all eight dimensions of the extended ACW could be explicitly addressed. Nevertheless, answers of the respondents were related also to ACW-dimensions, which were not explicitly addressed in the interview guideline, so that some interview data were also available for assessing variety, leadership, resources and fair governance. In the document analyses we could address all eight dimensions of adaptive capacity. Nevertheless, for some criteria of the ACW, due to lack of data, no assessment could be generated.

\subsubsection{Data analysis}

The collected documents and partly transcribed interviews were analysed based on the method of qualitative content analysis (Mayring, 2008) taking the extended ACW as the categorization scheme. To guarantee comparability and reliability of data analysis, the assessments were reviewed by another rater and discussed if raters disagreed in order to generate a consensual assessment. The different raters were all members of the project team. For example, the assessments by the rater, who primarily analysed the interview data and documents for the spatial/regional planning sector, were reviewed by the rater, who primarily analysed the data for civil protection. Whenever we use the words "rate" or "rating" we refer to subjective assessments of data from documents and interviews, of criteria of the ACW and of aggregations of criteria values by subjectively giving particular criteria higher weights. Whenever mere mathematical procedures are involved we use the word "calculate".

Figure 1 shows the eight dimensions and the 24 indicators of the ACW. Following Gupta et al. (2010) the inner circle symbolises adaptive capacity as a whole, the middle circle the dimensions and the outer circle the criteria. We rated the 22 criteria of the original ACW on five-level scales: very low $=1$, low $=2$, medium $=3$, high $=4$, very high $=5^{8}$. To gain values for the six dimensions of the original ACW we calculated arithmetic means of the respective criteria and rounded to whole numbers (e.g. means between 2.50 and 3.49 were rounded to $3=$ medium). Raters could deviate from this procedure and give specific criteria a higher weight, if the criteria were regarded as particularly important for the adaptive capacity of a sector. Such deviations had to be explicitly justified in the sector reports.

Based on the four-level scales used in the interviews, adaptation motivation and adaptation belief were rated on fourlevel scales (very low $=1$, low $=2$, medium $=3$, high $=4$ ). To generate sector-specific values, we calculated arithmetic means of all interview partner ratings for relevance (criterion

\footnotetext{
${ }^{8}$ We used this rating scheme in our data analyses because it was easier and more intuitive for us to use than the original scoring scheme by Gupta et al. (2010, p. 464) which uses the following scale: negative effect of institution on adaptive capacity $=-2$; slightly negative effect $=-1$; neutral or no effect $=0$; slightly positive effect $=1$; positive effect $=2$.
}

of adaptation motivation) and realisability of adaptation (criterion of adaptation belief) and rounded to whole numbers.

The overall sectorial adaptive capacities (middle circle) were rated as low, medium or high. Before the arithmetic mean of the eight dimensions of the extended ACW could be calculated the dimension values had to be normalised (values of the six dimensions by Gupta et al. were divided by 5 , the values of the two new dimensions were divided by 4) to give equal weights to all dimensions. Arithmetic means of these normalised dimension values were categorised as low (values from 0 to 0.33$)$, medium $(0.34$ to 0.66$)$ or high $(0.67$ to 1) sectorial adaptive capacity. Again, raters could deviate from this procedure and give specific criteria a higher weight, if the criteria were regarded as particularly important for the adaptive capacity of a sector.

\subsubsection{Data interpretation and presentation}

Following Gupta et al. (2010) the steps after data analysis were data interpretation and presentation. We prepared four sector reports that comprehensively describe the data and results for the 24 criteria of the extended ACW. For most criteria the data were sufficient to produce a text of at least one page, which describes the available data, their interpretation and relations to other criteria. Each criterion description concludes with a rating according to the rating scheme described in the previous section. This rating is explained by a short paragraph summing up the most important points of the text before, which justify the rating.

After all criteria descriptions for a particular dimension we state the dimension rating and justify it by a short paragraph summing up the respective criteria ratings and explaining, how the various criteria ratings are integrated to gain a dimension rating (in some cases by giving a particularly important criterion a higher weight).

Each sector report concludes with a visual presentation of a coloured ACW. Following Gupta et al. (2010) we used a traffic light system to visualise our assessments of the criteria, dimensions and the overall sectorial adaptive capacities, where green symbolises high values, yellow and orange medium values and red low values. Different from Gupta et al. (2010) we did not include any numbers in the visual presentations to avoid the impression of a high accuracy of our ratings.

\subsection{Exemplary results}

In the following, we mainly describe results for adaptation motivation and adaptation belief, because this paper focuses on our extension of the ACW by these two dimensions. The comprehensive analyses for flood/coastal protection can be found in Garrelts (2013a), for civil protection in Garrelts (2013b), for water management in Grecksch (2013a, b) and for spatial/regional planning in Winges (2013). Figure 3 illustrates the traffic light system for presenting the results of 
the ACW by the example of the ACW for water management in northwestern Germany.

We rated adaptation motivation as low in spatial/regional planning, medium in civil protection and water management, high in flood/coastal protection. In interpreting the levels of adaptation motivations it is important to mention that in flood/coastal protection and civil protection the interview partners stressed that there is no urgent need for adaptation to climate change because protection levels in their sectors would already be quite high. In water management there were clear indications that other topics, which compete with the adaptation topic for "organisational attention", were reducing organisations' adaptation motivation. In spatial/regional planning the adaptation motivations varied to a large extent between different regional entities within northwestern Germany. Furthermore, adaptation motivation differed also between levels of government.

Interestingly, in spatial/regional planning adaptation motivation was quite low compared to many other dimensions of the ACW that were rated as medium or high. The main reason for this result probably was the frustration of the interviewed actors regarding their lack of resources, especially of their authoritative resources, to implement adaptation measures. Because they perceived a lack of resources they were not very motivated to take adaptation action. This indicates that the different dimensions of the ACW are interconnected and that the factors assessed in these dimensions can influence each other. It seems plausible to assume that the "objective" factors such as resource availability assessed in the resources dimension have a strong influence on subjective adaptation motivations and adaptation beliefs of many actors whereas the factors assessed in other dimensions of the ACW (e.g. variety, learning capacity, leadership and fair governance) probably have a much lower impact on these subjective dimensions because factors like learning capacity are much less prevalent in people's minds than their (financial) resources.

Adaptation belief was assessed as low in water management, medium in spatial/regional planning, and high in flood/coastal protection and civil protection. While in the latter two sectors barriers to adaptation (e.g. lack of resources, existing conflicts) named by the interview partners in other parts of the interviews did not seem to have influenced their ratings of adaptation options' realisability, in water management and spatial/regional planning this was seemingly the case. In general, this might be due to the fact that the region itself so far did not experience any disasters in conjunction with natural extreme events - all storm surges, for example, could be coped with. Additional possible explanations for this difference might be, that interview partners from governmental agencies - as has been described before, most interview partners had this organisational background - in sectors, where the state has the explicit responsibility to protect citizens from harm, feel obliged to communicate high adaptation beliefs. Perhaps, this tendency to give socially desir- able answers has led to communication of higher adaptation beliefs than they actually are. Furthermore, the tendency to avoid blame might have played a role. If the interviewed actors had communicated low adaptation beliefs, they could be blamed for failing to fulfil their duties. Another explanation might be that they are afraid of causing panic reactions by showing doubts regarding the realisability of adaptation in their sectors, where there is the risk of fatal casualties if protection levels are not sufficient.

In water management the rating for adaptation belief, derived from the subjective assessments of adaptation options by the interviewed actors, was lower than for any other dimension of the ACW. Assuming that the six dimensions of the original ACW represent "objective" aspects of adaptive capacities this result can be interpreted as an indication that there is an underestimation of adaptive capacities by the actors in water management of northwestern Germany.

Contrary to this result, in civil protection the rating for adaptation belief was higher than for any other dimension of the ACW. This perception is probably rooted in a special professional ethos, that is, being always able and obliged to cope with extreme events (be it by improvisation); in the long run however, this might lead to an overestimation of capacities to cope with extreme events due to climate change.

\section{Discussion and conclusions}

The results indicate an added value of including the psychological/subjective dimensions adaptation motivation and adaptation belief in an extended ACW. For example, in spatial/regional planning the quite low adaptation motivation seems to be major barrier to adaptation, eventually caused by a lack of objective resources. The apparent underestimation of adaptive capacities in water management indicated that it might be useful to raise the awareness for the many objective adaptive strengths of this sector.

Therefore, the assessments of adaptation motivation and adaptation belief revealed practically useful and, in some cases, surprising results. The analysed sectors differed clearly on these psychological dimensions, which is a valuable information for adaptation governance because here the task often is to integrate adaptation measures in different sectors to avoid intersectorial conflicts (e.g. for space) and unwanted secondary effects from intersectorial interdependencies (e.g. water overuse). If actors in some sectors are less motivated to address adaptation to climate change this can become a barrier to involving them in such intersectorial coordination efforts.

Generally, adaptive capacity is not static, it is flexible and responds to changes in economic, social, political and institutional conditions over time (Smit and Wandel, 2006). Probably adaptation motivation and adaptation belief can change or can be changed (e.g. by information campaigns) faster than the other dimensions of the ACW. If this is really the 
case, this would have two important consequences: firstly, assessment of adaptation motivation and adaptation belief would have to be repeated more often than assessments of other ACW-dimensions to get an up-to-date assessment of institutional adaptive capacities. Secondly, changing adaptation motivation and adaptation belief can be seen as priorities for policy interventions if there is a need for quick increases in adaptive capacities. Nevertheless, adaptation motivation and adaptation belief are often not sufficient to realise adaptation measures. For example, if the feasible adaptation measure is costly, sufficient financial resources are necessary as well.

The denial of any urgent need for additional adaptation to climate change in flood/coastal protection and civil protection, as expressed by the interview partners - because protection levels in their sectors would already be quite high points to interdependencies of adaptation motivation and sensitivity to climate change. Indeed, the adaptation motivation ratings of the interview partners were obviously not strongly reduced by their trust in the sufficiency of current protection levels because there was still a medium motivation in civil protection and a high motivation in flood/coastal protection. Yet, it seems advisable to assess adaptation motivation based on more than just one indicator (in this study: perception of current relevance of adaptation to climate change in organisation). Including questions to also assess the perceptions of future relevance of adaptation as well as questions from classical risk perception surveys would minimise the danger of false positive (assessment of adaptation motivation as high) or false negative (assessments of motivation as low) ratings. Including further questions (perhaps in the form of questionnaires) also seems advisable for the assessment of adaptation beliefs, because answers of interview partners can be biased by the tendencies to give socially desirable answers and to avoid blame or panic (see Sect. 4.2).

The regional and organisational differences in adaptation motivations of the spatial/regional planning sector point to the importance of describing the variance of the adaptation motivation in addition to the average of motivation ratings of the interview partners because the sole communication of averages camouflages existing differences. This recommendation also applies for the other dimensions of the extended ACW.

Future studies should use five-level answer scales in the interviews for assessing adaptation motivation and adaptation belief. We have used four-level scales in the interviews to avoid a middle answer category, which is often chosen by respondents to avoid decisions. But in presenting our results for the extended ACW to stakeholders, the two different scales (four levels for adaptation motivation and adaptation belief, five levels for the six dimensions of the original ACW) decreased understandability for stakeholders.

Whether adaptation motivation and adaptation belief should be included as additional dimensions or be included as criteria in one or more of the six dimensions of the original
$\mathrm{ACW}$ is a question of theoretical perspective and the weight one would like to give these dimensions in assessing institutional adaptive capacities. Adaptation motivation and also the adaptation belief can be seen as necessary "psychological resources" for adaptation so that they could also be regarded as criteria of the resources dimension. Since they relate very much to motivations and beliefs of (potential) leaders of an adaptation process, they could also be regarded as criteria of the leadership dimension. If one understands them as very much driven by knowledge and learning - although there is not much evidence in empirical psychological research for this assumption - adaptation motivation and belief could be seen as further criteria of the learning capacity dimension.

We decided to include adaptation motivation and adaptation belief as additional dimensions to give them a high weight and visibility in the overall assessments of adaptive capacity because previous studies (e.g. Grothmann and Patt, 2005; Grothmann et al., 2009; Grothmann, 2011) have shown that a lack of adaptation motivation and adaptation belief are some of the most important barriers to adaptation. To reflect their common psychological quality they could also be put together as criteria of a seventh ACW-dimension that might be called "psychological capacities". As has been noted earlier, Kuhlicke et al. (2011, p. 806) refer to a further potentially important psychological factor: "sense of responsibility for one's own actions but also for those of other actors". If future empirical evidence shows the influence of this factor on adaptation, it could be included as a third criterion of the psychological capacities dimension, perhaps called "adaptation norm". This would result in three criteria for the psychological capacities dimension: adaptation motivation ("I/we want to adapt"), adaptation belief ("I/we can adapt") and adaptation norm ("I/we should adapt").

Generally, our analyses of the ACW dimensions and criteria revealed that the scientifically most interesting and practically most relevant results can be found in the qualitative analyses of the various criteria and dimensions. The averaged "quantitative" assessments (e.g. "low adaptation motivation in spatial/regional planning", "high motivation in flood/coastal protection"), which are visualised in the coloured ACWs, only provide a very rough overview of strengths and weaknesses in a particular sector, but do not suffice to present the various aspects of the assessments and to develop interventions to overcome the identified weaknesses.

Our analyses also confirmed the statement of Gupta et al. (2010, p. 465), "that the criteria are not additive in the sense that values given to each criterion can be simply added". It seems that an equal weighting of criteria can be very misleading, since some dimensions or criteria can be "weakest links" (Tol and Yohe, 2007) and a high value in these dimensions or criteria is a necessary prerequisite for adaptation. For example, if the feasible adaptation measures are very costly, but the economic resources for adaptation are very low, probably also the overall adaptive capacity has to 
be rated as very low even if all the other dimensions have high values. Or if the adaptation motivation is very low the necessary 'psychological resource' for adaptation is lacking so that the overall adaptive capacity is probably also very low.

Despite the described methodological challenges, the ACW is a useful heuristic to assess many social factors of adaptive capacity by addressing institutions, but also equity, information/skills and economic resources (cf. Smit and Pilifosova, 2001). The ACW does not address technology and infrastructure. Therefore, it should not be mistaken as an analytic tool to assess the adaptive capacities of social systems comprehensively.

As has been shown in Table 1, the ACW explicitly or implicitly addresses all the challenges of adaptation to climate change identified by Prutsch et al. (2014) and is much more operationalised and more differentiated with regard to the criteria for assessing institutional adaptive capacities than other frameworks for assessing adaptive capacities. Nevertheless is it applicable in a wide range of institutional settings. Other frameworks focus on sector-specific institutional settings (e.g. Hagedorn, 2002; Huntjens et al., 2012; Kuhlicke et al., 2011; Pahl-Wostl, 2009). Broader frameworks for institutional analysis, which often focus on socio-ecological systems (e.g. Folke et al., 2005; Ostrom, 2005, 2007, 2009), also claim - like Gupta et al. (2010) - to be applicable in various institutional settings, but are not focusing - like Gupta et al. (2010) - on climate change adaptation. For social capacity building the ACW, which has been developed for social capacity assessment, provides a useful first step by providing a detailed analysis of strengths and weaknesses of institutions to adapt to climate change. By its detailed analysis of social factors it sheds light on social dimensions of adaptive capacity which have as yet been neglected in studies on climate change vulnerability. Nevertheless, assessments based on the ACW are not specific enough to indicate which measures are suitable to increase a dimension of adaptive capacity that has been identified as a weakness. Which (policy) instruments are appropriate to make use of existing strengths in adaptive capacity and get over existing weaknesses is a question for future research.

Acknowledgements. This paper is part of the ongoing research project "nordwest2050 - Prospects for Climate-Adapted Innovation Processes in the Model Region Bremen-Oldenburg in northwestern Germany", funded by the Federal Ministry of Education and Research of Germany in the research program "Creating Climate Change-Ready Regions (KLIMZUG)".

Edited by: C. Kuhlicke

Reviewed by: three anonymous referees

\section{References}

Adger, W. N.: Vulnerability, Global Environ. Chang., 16, 268-281, 2006.

Adger, W. N., Agrawala, S., Mirza, M. M. Q., Conde, C., O’Brien, K., Pulhin, J., Pulwarty, R., Smit, B., and Takahashi, K.: Assessment of adaptation practices, options, constraints and capacity, in: Climate change 2007: Impacts, Adaptation and Vulnerability, Contribution of Working Group II to the Fourth Assessment Report of the Intergovernmental Panel on Climate Change, edited by: Parry, M. L., Canziani, O. F., Palutikof, J. P., van der Linden, P. J., and Hanson, C. E., Cambridge University Press, Cambridge, 717-743, 2007.

Adger, W. N., Dessai, S., Goulden, M., Hulme, M., Lorenzoni, I., Nelson, D. R., Naess, L. O., Wolf, J., and Wreford, A.: Are there social limits to adaptation to climate change?, Climatic Change, 93, 335-354, 2009.

APA - American Psychological Association: Psychology and global climate change - addressing a multifaceted phenomenon and set of challenges: a report of the American Psychological Association Task Force on the interface between psychology and global climate change, APA, Washington, DC, USA, 2010.

Berkhout, F.: Adaptation to climate change by organizations, Climate Change, 3, 91-106, 2012.

Brooks, N., Adger, W. N., and Kelly, P. M.: The determinants of vulnerability and adaptive capacity at the national level and the implications for adaptation, Global Environ. Chang., 15, 151163, 2005.

Carey, M., Huggel, C., Bury, J., Portocarrero, C., and Haeberli, W.: An integrated socio-environmental framework for glacier hazard management and climate change adaptation: lessons from Lake 513, Cordillera Blanca, Peru, Climatic Change, 112, 733-767, 2012.

Costa, L. and Kropp J. P.: Linking components of vulnerability in theoretic frameworks and case studies, Sustain. Sci., 8, 1-9, 2013.

Djalante, R., Thomalla, F., Sinapoy, M. S., and Carnegie, M.: Building resilience to natural hazards in Indonesia: progress and challenges in implementing the Hyogo Framework for Action, Nat. Hazards, 62, 779-803, 2012.

Folke, C., Hahn, T., Olsson, P., and Norberg, J.: Adaptive governance of social-ecological systems, Annu. Rev. Env. Resour., 30, 441-473, 2005.

Fowler, F. J. and Mangione, T. W.: Standardized Survey Interviewing, Minimizing Interviewer- Related Error, Sage, Newbury Park, 1990.

Füssel, H.-M. and Klein, J. T.: Climate change vulnerability assessments: an evaluation of conceptual thinking, Climatic Change, 75, 301-329, 2006.

Garrelts, H.: Ergebnisse für den Küsten- und Binnenhochwasserschutz, in: Vulnerabilität und Klimaanpassung: Herausforderungen adaptiver Governance im Nordwesten Deutschlands, nordwest2050-Werkstattbericht 23, edited by: Garrelts, H., Grothmann, T., Grecksch, K., Winges, M., Siebenhüner, B., and Flitner, M., Universität Bremen und Carl von Ossietzky Universität Oldenburg, Germany, 15-50, 2013a (in German).

Garrelts, H.: Ergebnisse für den Bevölkerungs- und Katastrophenschutz, in: Vulnerabilität und Klimaanpassung: Herausforderungen adaptiver Governance im Nordwesten Deutschlands, nordwest2050-Werkstattbericht 23, edited by: Garrelts, H., 
Grothmann, T., Grecksch, K., Winges, M., Siebenhüner, B., and Flitner, M., Universität Bremen und Carl von Ossietzky Universität Oldenburg, Germany, 51-81, 2013b (in German).

German Strategy for Adaptation to Climate Change, adopted by the German federal cabinet on 17 December 2008, The Federal Government of Germany, Berlin, 2008.

Grecksch, K.: Ergebnisse für die Wasserwirtschaft, in: Vulnerabilität und Klimaanpassung: Herausforderungen adaptiver Governance im Nordwesten Deutschlands. nordwest2050Werkstattbericht 23, edited by: Garrelts, H., Grothmann, T., Grecksch, K., Winges, M., Siebenhüner, B., and Flitner, M., Universität Bremen und Carl von Ossietzky Universität Oldenburg, Germany, 82-109, 2013a (in German).

Grecksch, K.: Adaptive Capacity and Regional Water Governance in North-western Germany, Water Policy 15, 794-815, 2013b.

Grothmann, T.: Governance recommendations for adaptation in European urban regions: results from five case studies and a European expert survey, in: Resilient Cities - Cities and Adaptation to Climate Change - Proceedings of the Global Forum 2010, edited by: Zimmermann, K.-O., Springer, Hamburg, 167-175, 2011.

Grothmann, T. and Patt, A.: Adaptive capacity and human cognition: the process of individual adaptation to climate change, Global Environ. Chang., 15, 199-213, 2005.

Grothmann, T. and Siebenhüner, B.: Reflexive governance and the importance of individual competencies: the case of adaptation to climate change in Germany, in: Reflexive Governance and Global Public Goods, edited by: Brousseau, E. Dedeurwaerdere, T., and Siebenhüner, B., MIT Press, Cambridge (MA), 299-314, 2012.

Grothmann, T., Nenz, D., and Pütz, M.: Adaptation in vulnerable alpine regions - lessons learnt from regional case studies, in: Regional Climate Change and Adaptation - The Alps Facing the Challenge of Changing Water Resources, edited by: European Environment Agency, EEA Report No 8/2009, EEA, Copenhagen, 96-108, 2009.

Grothmann, T., Daschkeit, A., Felgentreff, C., Görg, C., Horstmann, B., Scholz, I., and Tekken, V.: Anpassung an den Klimawandel - Potenziale sozialwissenschaftlicher Forschung in Deutschland, GAIA, 20, 84-90, 2011.

Gupta, J., Termeer, K., Klostermann, J., Meijerink, S., van den Brink, M., Jong, P., Nooteboom, S., and Bergsmaa, E.: The Adaptive Capacity Wheel: a method to assess the inherent characteristics of institutions to enable the adaptive capacity of society, Environ. Sci. Policy, 13, 459-471, 2010.

Hagedorn, K.: Institutional arrangements for environmental cooperatives: a conceptional framework, in: Environmental Cooperation and Institutional Change: Theories and Policies for European Agriculture, New Horizons in Environmental Economics, edited by: Hagedorn, K., Edward Elgar, Cheltenham, UK, and Northampton, MA, USA, 3-25, 2002.

Hoff, E.-H. and Walter, J.: Ökologische Kontrollvorstellungen: theoretische Überlegungen zu einem Teilkonzept im Projekt "Industriearbeit und ökologisches Verantwortungsbewußtsein", vol. 10, Berichte aus dem Bereich "Arbeit und Entwicklung" am Institut für Arbeits-, Organisations- und Gesundheitspsychologie der FU Berlin, Freie Universität Berlin, Berlin, Germany, 1996 (in German).

Huntjens, P., Lebel, L., Pahl-Wostl, C., Camkin, J., Schulze, R., and Kranz, N.: Institutional design propositions for the governance of adaptation to climate change in the water sector, Global Environ. Chang., 22, 67-81, 2012.

IDGEC Scientific Planning Committee: Institutional Dimensions of Global Environmental Change, IHDP Report No. 9, Bonn, 1999.

IPCC - Intergovernmental Panel on Climate Change: Climate Change 1995: Impacts, Adaptations and Mitigation of Climate Change: Summary for Policy Makers, World Meteorological Organisation, Geneva, 1996.

Jones, L. and Boyd, E.: Exploring social barriers to adaptation: insights from Western Nepal, Global Environ. Chang., 21, 12621274, 2011.

Kuhlicke, C., Steinführer, A., Begg, C., Bianchizza, C., Bründl, M., Buchecker, M., De Marchi, B., Di Masso Tarditti, M., Höppner, C., Komac, B., Lemkow, L., Luther, J., McCarthy, S., Pellizzoni, L., Renn, O., Scolobig, A., Supramaniam, M., Tapsell, S., Wachinger, G., Walker, G., Whittle, R., Zorn, M., and Faulkner, H.: Perspectives on social capacity building for natural hazards: outlining an emerging field of research and practice in Europe, Environ. Sci. Policy, 14, 804-814, 2011.

Lindell, M. K. and Perry, R. W.: Behavioral foundations of community emergency planning, Hemisphere, Washington, DC, 1992.

Lindell, M. K. and Perry, R. W.: The protective action decision model: theoretical modifications and additional evidence, Risk Anal., 32, 616-632, 2012.

Mayring, P.: Qualitative Inhaltsanalyse, Grundlagen und Techniken, Beltz, Weinheim, 2008.

McCarthy, J. J., Canziani, O. F., Leary, N. A., Dokken, D. J., and White, K. S.: Climate Change 2001: Impacts, Adaptation, and Vulnerability, Contribution of Working Group II to the Third Assessment Report of the Intergovernmental Panel on Climate Change, Cambridge University Press, Cambridge, 1032 pp., 2001.

Merton, R. K. and Kendall, P. L.: The focused interview, Am. J. Sociol., 51, 541-557, 1946/1979.

Meuser, M. and Nagel, U.: ExpertInneninterviews - vielfach erprobt, wenig bedacht. Ein Beitrag zur qualitativen Methodendiskussion, in: Qualitativ-empirische Sozialforschung, edited by: Garz, D. and Kraimer, K., Westdeutscher Verlag, Opladen, 441-468, 1991 (in German).

Moser, S. C. and Ekstrom, J. A.: A framework to diagnose barriers to climate change adaptation, P. Natl. Acad. Sci. USA, 107, 22026-22031, 2010.

Mulilis, J. P. and Duval, T. S.: The PrE model of coping and tornado preparedness: moderating effects of responsibility, J. Appl. Soc. Psychol., 27, 1750-1766, 1997.

O'Brien, K. L.: Do values subjectively define the limits to climate change adaptation, in: Adapting to Climate Change: Thresholds, Values, Governance, edited by: Adger, W. N., Lorenzoni, I., and O’Brien, K. L., Cambridge University Press, Cambridge, 164180, 2009.

Pahl-Wostl, C.: A conceptual framework for analysing adaptive capacity and multi-level learning processes in resource governance regimes, Global Environ. Chang., 19, 354-365, 2009.

Ostrom, E.: Understanding Institutional Diversity, Princeton University Press, Princeton, 2005.

Ostrom, E.: A diagnostic approach for going beyond panaceas, P. Natl. Acad. Sci. USA, 104, 15181-15187, 2007.

Ostrom, E.: A general framework for analyzing sustainability of social-ecological systems, Science, 325, 419-422, 2009. 
Prutsch, A., McCallum, S., Grothmann, T., Schauser, I., and Swart, R.: Facing the specific challenges of adaptation, in: Climate Change Adaptation Manual - Lessons Learned from European and Other Industrialized Countries, edited by: Prutsch, A., Grothmann, T., McCallum, S., Schauser, I., and Swart, R., Routledge, London, UK, and New York, USA, 7-13, 2014.

Rogers, R. W.: Cognitive and physiological processes in fear appeals and attitude change: a revised theory of protection motivation, in: Social Psychophysiology: a Sourcebook, edited by: Cacioppo, B. L. and Petty, L. L., Guilford, London, 153-176, 1983.

Rogers, R. W. and Prentice-Dunn, S.: Protection motivation theory, in: Handbook of Health Behaviour Research. I: Personal and Social Determinants, edited by: Gochman, D. S., Plenum Press, New York, 113-132, 1997.

Smit, B. and Pilifosova, O.: Adaptation to Climate Change in the Context of Sustainable Development and Equity, in: Climate Change 2001: Impacts, Adaptation, and Vulnerability - Contribution of Working Group II to the Third Assessment Report of the Intergovernmental Panel on Climate Change, edited by: McCarthy, J. J., Canzianni, O. F., Leary, N. A., Dokken, D. J., and White, K. S., Cambridge University Press, Cambridge, 877-912, 2001.

Smit, B. and Wandel, J.: Adaptation, adaptive capacity and vulnerability, Global Environ. Chang., 16, 282-292, 2006.

Tol, R. S. J. and Yohe, G. W.: The weakest link hypothesis for adaptive capacity: an empirical test, Global Environ. Chang., 17, 218 227, 2007.

UNDP - United Nations Development Programme: Designing Climate Change Adaptation Initiatives - A UNDP toolkit for practitioners, UNDP, New York, NY, 2010.
Weber, E. U.: Perception and expectation of climate change: precondition for economic and technological adaptation, in: Psychological Perspectives to Environmental and Ethical Issues in Management, edited by: Bazerman, M. H., Messick, D. M., Tenbrunsel, A., and Wade-Benzoni, K., Jossey-Bass, San Francisco, CA, 314-341, 1997.

Werg, J., Grothmann, T., and Schmidt, P.: Assessing social capacity and vulnerability of private households to natural hazards - integrating psychological and governance factors, Nat. Hazards Earth Syst. Sci., 13, 1613-1628, doi:10.5194/nhess-131613-2013, 2013.

Winges, M.: Ergebnisse für Raum- und Regionalplanung, in: Vulnerabilität und Klimaanpassung: Herausforderungen adaptiver Governance im Nordwesten Deutschlands, nordwest2050Werkstattbericht 23, edited by: Garrelts, H., Grothmann, T., Grecksch, K., Winges, M., Siebenhüner, B., and Flitner, M., Universität Bremen und Carl von Ossietzky Universität Oldenburg, 109-144, 2013 (in German).

Witzel, A.: Das problemzentrierte Interview, in: Qualitative Forschung in der Psychologie, edited by: Jüttemann, G., Beltz, Weinheim, 227-255, 1985.

Witzel, A.: Das problemzentrierte Interview, Forum Qualitative Social Research, 1, 22, 2000.

Zebisch, M., Grothmann, T., Schröter, D., Haße, C., Fritsch, U., and Cramer, W.: Climate change in Germany. Vulnerability and adaptation of climate sensitive sectors, Report 20141 253, Federal Environmental Agency Germany, Dessau, Germany, 2005. 